\title{
artigo
}

Borges, A.M.; Sulzbacher, A.; Mello, M.C.V.A.

Perfil epidemiológico da Hepatite B: Conhecer para prevenir

DOI: https://doi.org/10.36489/saudecoletiva.2020v10i52p2080-2093

\section{Perfil epidemiológico da Hepatite B: Conhecer para prevenir}

\author{
Epidemiological profile of Hepatitis B: Knowing to prevent \\ Perfil epidemiológico da Hepatitis B: Conocer para prevenir
}

Vinculação do manuscrito: Oriundo de trabalho monográfico.

\begin{abstract}
RESUMO
Objetivos: Descrever o perfil epidemiológico dos casos notificados de Hepatite B do município de Santa Cruz do Sul, Rio Grande do Sul, no período de 2011 a 2016, bem como, elaborar um mapa contendo o número de casos notificados de hepatite B, dispostos no município. Método: Estudo epidemiológico descritivo, a partir de dados secundários do Sistema de Informação de Agravos e Notificação, obtido junto ao Centro Municipal de atendimento à sorologia realizada no ambulatório de hepatites virais. Os dados foram organizados no programa Microsoft Office Excel e após, conduzida a análise da frequência absoluta e média aritmética. Resultados: Foram notificados 54 casos de hepatite B, com predomínio do sexo masculino, faixa etária de 40 a 50 anos, área urbana, 46 casos notificados com ausência da vacina contra o VHB e 36 ignorados quanto à provável fonte de infecção. Conclusões: 0 cenário desfavorável ao efetivo registro notificatório da doença e condição vacinal, evidenciou o quanto é necessário investir na educação em saúde e ampliação da cobertura à população adulta.
\end{abstract}

DESCRITORES: Hepatite B; Enfermagem; Epidemiologia.

\section{ABSTRACT}

Objectives: To describe the epidemiological profile of the reported cases of Hepatitis B in the municipality of Santa Cruz do Sul, Rio Grande do Sul, from 2011 to 2016, obtained from the Municipal Serology Center. Develop a map containing the number of notified cases of hepatitis B, arranged in the municipality. Method: Descriptive epidemiological study, based on secondary data from the Notification Aggravation Information System, performed in the outpatient clinic for viral hepatitis. Results: 54 cases of hepatitis B, predominantly of males, aged between 40 and 50 years, urban area, 46 cases reported with absence of HBV vaccine and 36 were ignored regarding the probable source of infection. Conclusions: The scenario unfavorable to the effective registry of disease and vaccination status, evidenced how much it is necessary to invest in health education and to increase coverage to the adult population.

DESCRIPTORS: Hepatitis B; Nursing; Epidemiology.

\section{RESUMEN}

Objetivos: Describir el perfil epidemiológico de los casos notificados de Hepatitis B del municipio de Santa Cruz do Sul, Rio Grande do Sul, en el período de 2011 a 2016, obtenido junto al Centro Municipal de atención a la serología. Elaborar un mapa conteniendo el número de casos notificados de hepatitis B, dispuestos en el municipio. Métodos: Estudio epidemiológico descriptivo, a partir de datos secundarios del Sistema de Información de Agravios y Notificación, realizada en el ambulatorio de hepatitis virales. Resultados: Se notificaron 54 casos de hepatitis B, con predominio del sexo masculino, grupo de edad de 40 a 50 años, área urbana, 46 casos notificados con ausencia de la vacuna contra el VHB y 36 ignorados en cuanto a la probable fuente de infección. Conclusiones: El escenario desfavorable al efectivo registro notificatorio de la enfermedad y condición vacunal, evidenció cuán necesario es invertir en la educación en salud y ampliar la cobertura a la población adulta.

DESCRIPTORES: Hepatitis B; Enfermería; Epidemiología.

RECEBIDO EM: 15/12/2019 APROVADO EM: 15/12/2019

\section{Anelise Miritz Borges}

Enfermeira, Doutora em Enfermagem pela Escola de Enfermagem junto à Universidade Federal do Rio Grande (FURG). Docente do Curso de Enfermagem. Departamento de Enfermagem e Odontologia da Universidade de Santa Cruz do Sul (UNISC), Santa Cruz do Sul (SCS), Rio Grande do Sul (RS), Brasil. https://orcid.org/0000-0002-3279-7849 


\section{Alessandro Sulzbacher}

Enfermeiro, pelo Curso de Enfermagem da UNISC. Atua na Empresa Transul Emergências Médicas em Candelária, RS, Brasil. https://orcid.org/0000-0003-3734-2752

\section{Marlise Capa Verde de Almeida de Mello}

Enfermeira, Doutora em Enfermagem pela Escola de Enfermagem junto à Universidade Federal do Rio Grande (FURG). Enfermeira Técnica do Laboratório de Práticas em Enfermagem (LabEnf) e Laboratório Socioambiental em Saúde do Trabalhador (LASTRA) da Escola de Enfermagem da FURG. Rio Grande, RS, Brasil. https://orcid.org/0000-0002-8466-3420

\section{INTRODUÇÃO}

A proximadamente um terço da população mundial já foi exposta ao vírus da hepatite $\mathrm{B}(\mathrm{VHB})$, estima-se que 240 milhões de pessoas estejam infectadas cronicamente $^{(1)}$. A doença é responsável por cerca de 780.000 óbitos ao ano no mundo, sendo a décima causa de morte, fato que passou a se tornar um problema de saúde pública, tanto no Brasil, quanto no mundo ${ }^{(2)}$. No Brasil, esta doença representa a segunda maior causa de óbitos entre as hepatites virais, de 2000 a 2016, foram identificados 14.172 óbitos, sendo a maior parte na região Sudeste $-41,7 \%{ }^{(3)}$.

De acordo com as informações do Boletim Epidemiológico de 2018, o Sistema de Informação de Agravos de Notificação (SINAN), contou com 200.839 casos confirmados para a hepatite B, entre 1999 a 2017, ou seja, 34,2\% da população brasileira, o que reflete em aproximadamente um terço ${ }^{(3)}$. Esta asseveração comprova o alto índice de pessoas com evidências sorológicas de infecção por este antígeno, seja no passado ou presente ${ }^{(4)}$.

O VHB possui elevada transmissibilidade e é o tipo mais grave das hepatites, sua manifestação pode ser aguda grave ou causar hepatopatia crônica ${ }^{(5,6)}$. Está incluída na lista de doenças de notificação compulsória, por conseguinte, os profissionais de saúde têm papel importante na notificação e no acompanhamento das pessoas portadoras, sintomáticas ou não ${ }^{(6)}$.

Entre os casos notificados no SINAN no período de 1999 a 2017, foi verificada que a principal forma clínica diante da confirmação dos casos foi a crônica, representando $72,4 \%$ do total ${ }^{(3)}$, o que denota que a maioria das pessoas desconhece a sua condição sorológica, agravando ainda mais a cadeia de transmissão da infecção devido ao tempo que convivem com a doença sem saber que a possuem.
No ano de 2016, apenas uma em cada 20 pessoas, que contraiu a hepatite viral, tinha conhecimento de sua infecção, e somente um em cada 100 enfermos, recebeu o tratamento $^{(5)}$. Esta condição contribui para a manifestação de complicações das formas agudas, seguido da cronificação (2).

Ademais, a desinformação é um dos principais problemas diante da manifestação da doença, por esta razão, é importante a realização de campanhas de educação em saúde com a comunidade. Ação que contribui para a redução dos gastos públicos, muito oriundos das internações hospitalares prolongadas, demandando um acompanhamento ao longo do curso da doença, muitas vezes, nos três níveis de atenção em saúde ${ }^{(2)}$.

De acordo com a Organização Pan-Americana de Saúde (OPAS) e a Organização Mundial de Saúde (OMS), foram criadas as primeiras metas e estratégias globais para reduzir a hepatite viral no mundo, cuja ação consiste em tratar oito milhões de pessoas que sofrem de hepatite B ou C até 2020 e, reduzir em 90\% à incidência de hepatite viral e, em $65 \%$ a mortalidade destas doenças até 2030, o que representaria a sua eliminação como problema de saúde pública ${ }^{(7)}$. Logo, a atuação por meio de estudos epidemiológicos contribui para avaliar o impacto de doenças e intervenções em saúde ${ }^{(8)}$.

Para tanto, apresenta-se como como questão norteadora: Qual o perfil epidemiológico dos casos notificados de hepatite B em Santa Cruz do Sul? Qual o número de portadores de hepatite $\mathrm{B}$ por sexo e faixa etária, dispostos nos bairros e distritos do município?

Dessa forma, objetivou-se, descrever o perfil epidemiológico dos casos notificados de hepatite B do município de Santa Cruz do Sul e elaborar um mapa contendo o número de portadores de hepatite $\mathrm{B}$ por sexo e faixa etária, dispostos nos bairros e distritos do município.

\section{METODOLOGIA}

Trata-se de um estudo epidemiológico de caráter descritivo, a partir de dados secundários, conduzido na cidade de Santa Cruz do Sul, no Rio Grande do Sul (RS), junto ao Centro Municipal de Atendimento à Sorologia (CEMAS), o qual presta atendimento de média complexidade no âmbito do Sistema Único de Saúde (SUS).

Foram analisados todos os casos de hepatite B confirmados no período de 2011 a 2016, em adultos, com idades a partir de 18 anos, que residiam no referido município, notificados na ficha de investigação do Sistema de Informação de Agravos de Notificação (SINAN).

A coleta de dados ocorreu no período de agosto a setembro de 2017, por meio da definição das seguintes variáveis: sexo, idade, cobertura vacinal, fator de risco, provável fonte $\backslash$ mecanismo de infecção, tipo de exposição e localização.

Para a análise dos dados, estes foram organizados no programa Microsoft Office Excel e após, conduzida a análise da frequência absoluta e média aritmética dos dados, os quais foram estruturados em tabelas, gráficos e mapas.

A elaboração do mapa contou com o apoio do Professor Bruno Depra, vinculado ao núcleo de gestão pública da Universidade de Santa Cruz do Sul, para tal, foi solicitado estruturar um mapa contendo a divisão territorial por bairros e distritos em que haviam unidades básicas de saúde no município e, junto a elas, incluir o número de casos notificados e o sexo feminino ou masculino, conforme o SINAN.

Quanto aos preceitos éticos, estes foram respeitados, sendo solicitada a autorização para a Secretaria Municipal de Saúde, com justificativa para a ausência do Termo de Consentimento Livre e Esclarecido, obtendo-se o parecer favorável para a condução do estudo. 


\section{RESULTADOS}

Foram notificados 54 casos de hepatite B no período de 2011 a 2016, na cidade

Gráfico 1. Distribuição das notificações de hepatite B, conforme o ano de notificação e a linha de tendência. Santa Cruz do Sul, RS, Brasil, 2017.

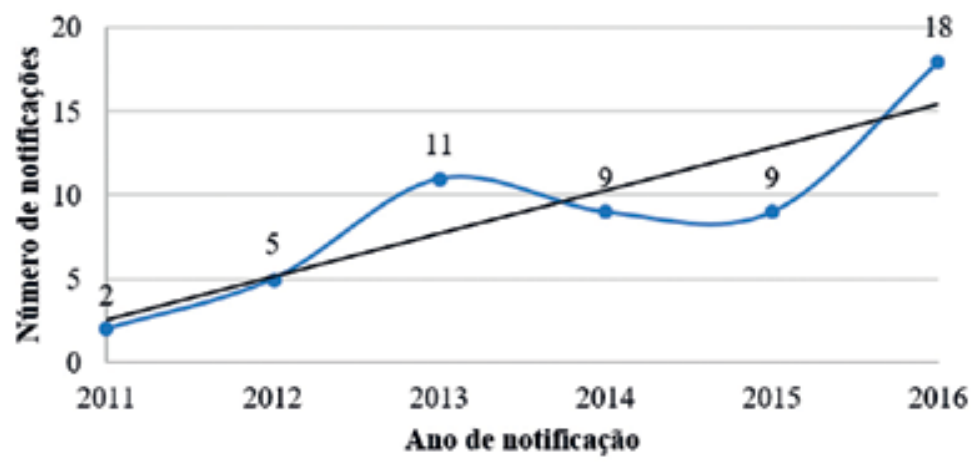

Gráfico 2. Distribuição das notificações para hepatite B conforme o sexo. Santa Cruz do Sul, RS, Brasil, 2017.

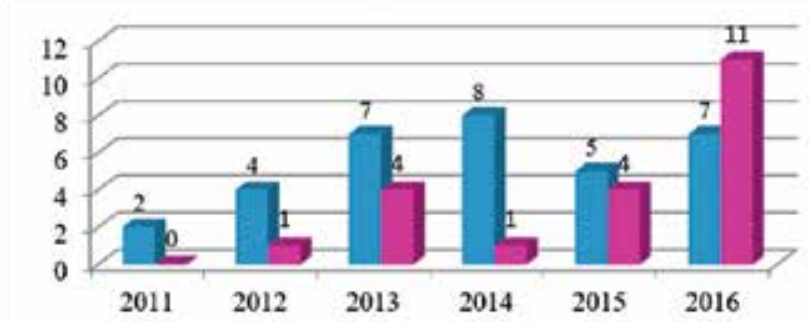

= Masculino

= Feminino

Tabela 1. Fatores de risco identificados por confirmação laboratorial entre os 54 casos notificados por hepatite B. Santa Cruz do Sul, RS, Brasil, 2017.

$\begin{array}{lllllll}\text { VARIÁVEIS } & 2011 & 2012 & 2013 & 2014 & 2015 & 2013\end{array}$

$\begin{array}{llllll}(\mathrm{N}: 02) & (\mathrm{N}: 05) & (\mathrm{N}: 11) & (\mathrm{N}: 09) & (\mathrm{N}: 09) & (\mathrm{N}: 18)\end{array}$

INSTITUCIONALIZADO

$\begin{array}{lccccccc}\text { Não } & 02 & 05 & 11 & 08 & 08 & 17 & 51 \\ \text { Sim (Penitenciária) } & - & - & - & 01 & 01 & 01 & 03 \\ \begin{array}{l}\text { CONTATO COM } \\ \text { PACIENTE PORTADOR }\end{array} & & & & & & & \\ \text { VHB } & & & & & & & \\ \begin{array}{l}\text { Domiciliar (não } \\ \text { sexual) }\end{array} & - & - & 01 & 02 & 02 & 03 & 08 \\ \text { Sexual } & - & - & - & - & 01 & 02 & 03 \\ \text { Ocupacional } & - & - & - & - & 01 & 01 & 02 \\ \text { Não } & - & 04 & 08 & 07 & 05 & 11 & 34 \\ \text { Ignorada } & 02 & 01 & 02 & - & 02 & 03 & 10\end{array}$

Nota: VHB: Vírus hepatite B. Ignorada: Não sabe. Não quis responder. Não foi perguntado.
Quanto ao perfil dos casos notificados por hepatite B (Gráfico 2) em Santa Cruz do Sul, houve o predomínio de 33 casos do sexo masculino e 21 casos do feminino. Apesar do predomínio do sexo masculino no período analisado, no ano de 2015 o número de casos entre os homens teve uma redução, diferentemente do sexo feminino, quando em 2016, o número de casos quase triplicou.

A faixa etária mais acometida por hepatite $\mathrm{B}$ no período analisado foi de 40 a 50 anos, seguida daqueles entre 51 a 61 anos, sendo que neste período etário não foram identificados idosos. Contudo, as idades entre 62 a 72 anos, foram identificados sete idosos, o que significa diante das fases da vida, que os adultos se encontram mais atingidos pela doença.

Outro aspecto avaliado foi a cobertura vacinal, que direcionou um alerta ao serviço de atenção primária, pois, do total de notificações, sete apresentaram o esquema completo para a hepatite $B$ e 46 não possuíam a vacina.

Quanto aos fatores de risco (Tabela 1), dos 54 casos, três estavam institucionalizados e vinculados à casa prisional de SCS. Destes, dois casos não tiveram contato com portador do $\mathrm{VHB}$ e o outro foi ignorado. Não obstante, ao relacionar a exposição para a doença, os três participantes detentos utilizavam medicamentos injetáveis e drogas inaláveis ou crack. Dois deles também utilizavam drogas injetáveis, possuíam três ou mais parceiros sexuais e tinham realizado tratamento dentário.

Entre os 51 casos não institucionalizados, 34 não tiveram contato com paciente portador do VHB, havendo, ainda, outros fatores que aumentaram potencialmente a probabilidade de ocorrência da doença, como a via domiciliar, sexual ou ocupacional.

Outro fator preocupante incide na provável fonte de infecção (Tabela 2), pois no período analisado, foram 36 casos ignorados, isso quer dizer que o paciente não sabia, não quis responder ou ainda, quem realizou a notificação não perguntou ao paciente sobre a origem. Fato que fragiliza a interpretação dos resultados e salienta a importância de profissionais atentos para 
Tabela 2. Provável fonte/mecanismo de infecção por hepatite B nos 54 casos notificados de 2011 a 2016. Santa Cruz do Sul, RS, Brasil, 2017.

$\begin{array}{cccccccc}\text { VARIÁVEIS } & 2011 & 2012 & 2013 & 2014 & 2015 & 2013 & \text { TOTAL } \\ & \text { (N: 02) } & \text { (N: 05) } & \text { (N: 11) } & \text { (N: 09) } & \text { (N: 09) } & \text { (N: 18) } & \end{array}$

$\begin{array}{lccccccc}\text { Sexual } & - & - & 03 & 01 & 03 & 02 & 09 \\ \text { Transfusional } & - & - & 01 & - & - & 02 & 03 \\ \text { Uso de drogas } & - & - & - & 01 & - & - & 01 \\ \text { Vertical } & - & - & 02 & 01 & - & - & 03 \\ \text { Acidente de trabalho } & - & - & - & - & - & - & - \\ \text { Hemodiálise } & - & - & - & - & - & - & - \\ \text { Domiciliar } & - & - & 01 & - & - & - & 01 \\ \text { Tratamento cirúrgico } & - & - & - & - & - & - & - \\ \text { Tratamento dentário } & - & - & - & - & - & - & - \\ \text { Pessoa/pessoa } & - & - & - & - & - & - & - \\ \text { Outros } & - & - & - & - & - & 01 & 01 \\ \text { Ignorado } & 02 & 05 & 04 & 06 & 06 & 13 & 36\end{array}$

Figura 1. Mapa dos casos de hepatite B. Santa Cruz do Sul, RS, Brasil, 2011 a 2016.

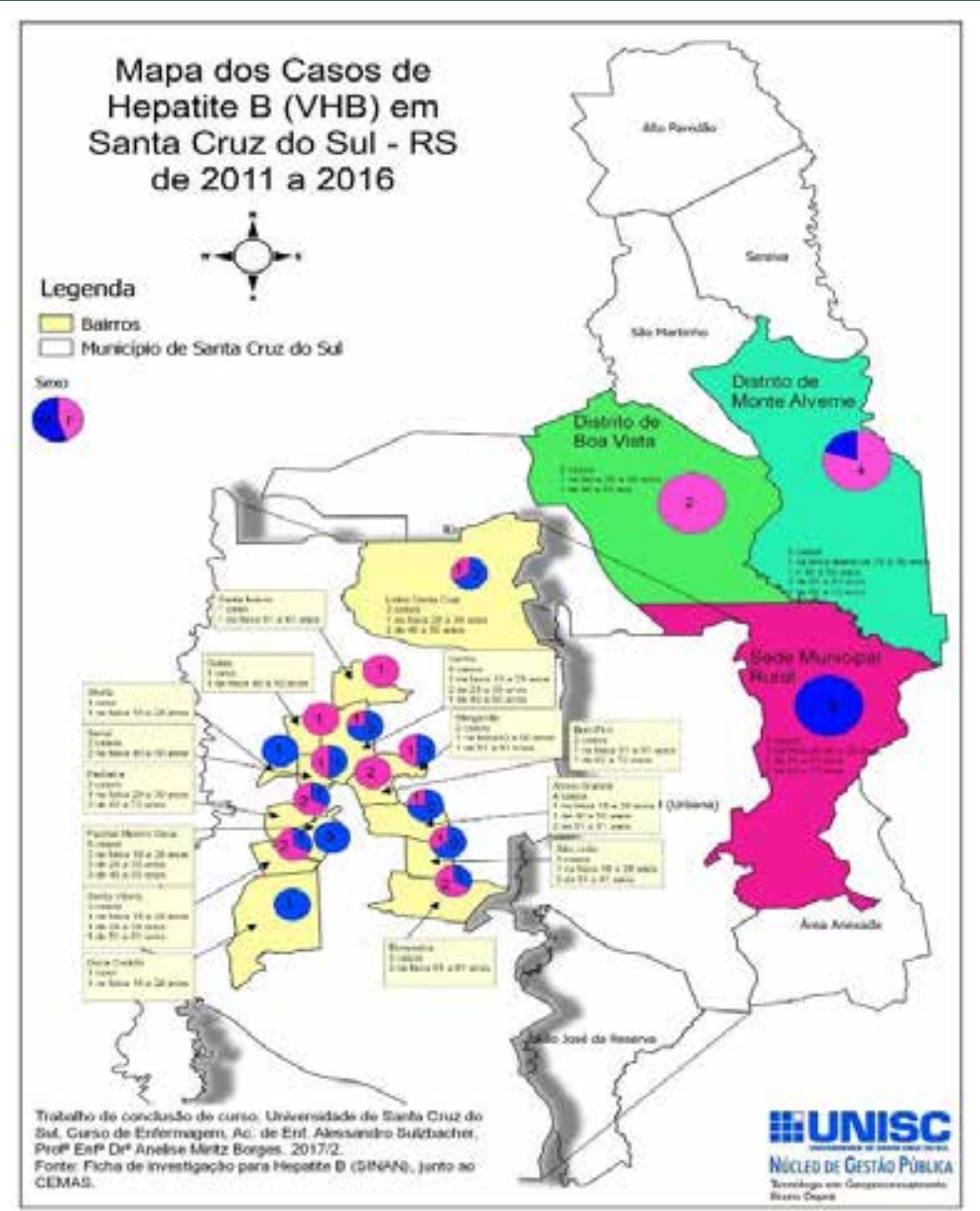

o manuseio da notificação.

Ao redirecionar o olhar à Tabela 2, verifica-se que a fonte de infeção mais presente foi por meio da relação sexual, adicionalmente, informa-se que este mecanismo prevaleceu para os homens, com oito casos notificados e apenas um às mulheres, $\mathrm{e}$ que a idade destes participantes variou de 21 a 49 anos de idade, dado significativo e preocupante, pois muitos ainda jovens, talvez não possuíssem o devido cuidado ao realizar a atividade sexual.

Dos 54 casos notificados, cinco tinham algum agravo associado, destes, três tinham Vírus da Imunodeficiência Humana (HIV/AIDS) e dois tinham outras Infecções Sexualmente Transmissível (ISTs). Quanto ao sexo destes cinco participantes, quatro eram homens e apenas uma era mulher, a idade variou de 21 a 40 anos e todos tinham apresentado exposição a algum fator de risco, como drogas inaláveis ou crack, três ou mais parceiros sexuais, tatuagem/piercings, acupuntura, tratamento cirúrgico e tratamento dentário.

Quanto à localização dos casos notificados com o VHB dentro do território do município de Santa Cruz do Sul (Figura 01), foi possível perceber que houve uma certa dificuldade por parte dos profissionais que manuseiam o SINAN, para realizarem a distinção entre a zona rural e a urbana, este fato se explica devido a carência na divulgação da divisão territorial correta. Portanto, para apresentar os dados junto ao mapa, a divisão territorial foi considerada, sendo possível identificar que o maior número de notificações ocorreu junto ao bairro Faxinal/Menino Deus, com oito casos, todos estes do sexo masculino e com idades entre 18 a 50 anos. Seguido da região central da cidade com idades entre 26 a 42 anos e do bairro Arroio Grande entre 27 a 55 anos, ambas localidades com quatro casos cada.

\section{DISCUSSÃO}

Dentre as metas até 2030, previstas pela Organização Pan-americana de Saúde (OPAS) frente às hepatites virais, está a realização de $90 \%$ de testes e $80 \%$ da oferta de 
tratamentos para hepatites $\mathrm{B} \mathrm{e} \mathrm{C}^{(9)}$. Tais iniciativas são importantes, haja vista que o índice de mortalidade em 2016, no Brasil, para a razão de sexos, foi de 28 óbitos entre homens, para cada 10 óbitos entre mulheres ${ }^{(3)}$.

As taxas de detecção de hepatite $\mathrm{B}$, em nosso país, desde o início da notificação compulsória da doença em 1999, foram superiores para as regiôes Sul, Norte e Centro Oeste, diante da taxa nacional ${ }^{(1)}$. Ao direcionar o olhar ao Sul, em Santa Cruz do Sul, constata-se que os números elevados de notificação em 2013 podem ser justificados pela maior mobilização dos serviços de saúde na atenção primária, na detecção de casos pela testagem rápida das hepatites $\mathrm{Be} \mathrm{C}^{(7)}$.

Diante da distribuição dos casos notificados de hepatite B junto ao Centro Estadual da Vigilância em Saúde do RS, a cada 100.000 habitantes teve-se uma tendência de aumento dos casos de 2011 a 2015 e após, uma redução no ano de $2016^{(6)}$. Ao comparar com os dados de SCS, verifica-se que este último ano foi atípico e impactante para o município, pois dobrou o número de casos frente ao ano anterior, o que pode estar relacionado com o impacto do trabalho de educação, incentivando o cuidado em saúde, riscos e condutas para diagnóstico e tratamento.

Houve também uma grande mobilização no ano de 2016 da Secretaria Municipal de Saúde na realização de campanhas de prevenção e sensibilização sobre a hepatite B em SCS. Foram capacitações conduzidas pelo Laboratório Central de Saúde Pública do Rio Grande do Sul (Lacen), atuação efetiva de representantes da SMS, apoio da Universidade de Santa Cruz do Sul, além da presença de um ônibus com profissionais capacitados para realizar atividades informativas sobre a prevenção da doença à comunidade santa-cruzense ${ }^{(10)}$. Todas estas ações remetem a um grande empenho do município na prevenção e nas notificações de hepatite $B$, o que pode ter contribuído para a elevação dos casos confirmados.

Na estratificação por sexos, em 2017, o maior percentual de casos notificados no Brasil foi para o masculino, com idades entre 30 a 44 anos ( $36,8 \%$ dos casos), o que também ocorreu no acumulado de casos entre 1999 a 2017, obtendo prevalência masculina com idades entre 25 a 49 anos $(60,5 \%)$. Entre os casos femininos, neste período de mais de uma década, a idade com maior notificação foi entre 20 a 39 anos - $53,7 \%(3)$. O oposto frente ao sexo foi identificado no Espírito Santo, com predomínio de casos femininos e idades entre 20 a 49 anos. Fato possivelmente explicado devido a tendência de as mulheres recorrerem mais aos serviços de saúde ${ }^{(11)}$.

A tendência de notificações de hepatite B para o sexo masculino foi evidenciada em demais estudos, como em Salvador, no Estado da Bahia ${ }^{(12)}$ e em Montes Claros, Minas Gerais ${ }^{(13)}$, este último aponta que $90,2 \%$ eram adultos com idades até 44 anos, obtendo a faixa etária idosa com menor prevalência, o que é compatível com a presente pesquisa em SCS.

Constata-se que a provável fonte ou mecanismo de infecção por hepatite $\mathrm{B}$, entre 2007 a 2017, no Brasil, foi via sexual ${ }^{(3)}$, o que consensua com os achados na presente pesquisa. Não obstante, o Manual Técnico de Hepatites aponta as demais possíveis fontes, como: a via parenteral (compartilhamento de agulhas e seringas, procedimentos odontológicos/cirúrgicos, tatuagens, piercings), também objetos de higiene pessoal (escovas de dente, alicates de unha, lâminas de barbear ou depilar), leite materno e transmissão vertical (de mãe para filho). Além de acidentes de trabalho, hemodiálise e via domiciliar ${ }^{(3)}$. O com $\neg$ portamento de risco, possivelmente, está atrelado à contaminação via sexual, mas também à presença de múltiplos parceiros e à falta de proteção durante as relações sexuais, em que a disseminação de IST é iminente ${ }^{(13)}$.

É importante reconhecer que a abordagem sobre a vivência sexual necessita superar estigmas e preconceitos relacionados às perspectivas heteronormativas e, sim, considerar os valores e desigualdades permeados em cada cultura e evolução humana, a fim de acolher de forma adequada a diversidade e a singularidade de cada sujeito ${ }^{(14)}$.

$\mathrm{O}$ aparecimento do agravo decorrente da hepatite $B$ também foi relacionado com o tratamento cirúrgico ${ }^{(3)}, \operatorname{logo}$, é preciso saber que o vírus consegue sobreviver em superfície seca por até sete dias e é considerado muito mais infeccioso do que o HIV.

Atenção para a realização de tatuagens, em sua maioria com métodos caseiros (dentro das unidades prisionais ou em sua própria residência), assim como o uso de drogas injetáveis e a baixa escolaridade ${ }^{(15)}$. Já em localidades ribeirinhas do Rio Madeira, a extração dentária e o histórico de cirurgia foram os mais citados ${ }^{(4)}$.

Além do uso de drogas injetáveis, do tratamento odontológico e contágio via sexual com indicação de múltiplos parceiros, o contato domiciliar com outra pessoa infectada pelo HBV também foi destacado ${ }^{(11)}$. A coinfecção com o HIV entre os casos notificados de hepatite B foi observada em 5,2\% dos casos acumulados no período de 2007 a 2017, com elevação para a região Sudeste do Brasil, o que reitera a importância do diagnóstico, facilitado gratuitamente por meio dos testes rápidos ${ }^{(3)}$.

No Rio Grande do Sul, no ano de 2017, foram realizados 235.697 testes rápidos para hepatite $B$, com a disponibilidade em 457 municípios, em pelo menos uma unidade de saúde, evento a ser expandido a todos os municípios gaúchos até o ano de 2019, conforme a meta prevista no Plano Estadual de Saúde ${ }^{(6)}$.

Outro motivo incide na baixa adesão à imunização, muitas vezes devido a carência de orientaçóes, o que confere menor proteção à infecção pela hepatite $\mathrm{B}^{(13)}$. Os programas de educação em saúde são essenciais, abordando a importância da vacinação na prevenção da doença em questão, assim como, da inclusão de busca ativa para àqueles que não completaram o esquema vacinal ${ }^{(16)}$. Esta atenção necessita ser incentivada, pois o imunobiológico é disponível de forma gratuita pelo SUS nas unidades de atenção primária dos municípios ${ }^{(7)}$, o que denota vigilância, principalmente entre as populações com baixa ou sem escolaridade e residentes em áreas rurais ${ }^{(17)}$

A Estratégia Global do Setor da Saúde da OMS, em 2015, apontou uma estimativa de que 2,7 milhões de pessoas foram co-infectadas pelo HBV, sendo que 257 milhões de pessoas viviam com o vírus sob forma crônica no mundo. Uma das justifi- 
cativas esteve relacionada com a indisponibilidade da vacina diante do nascimento destas pessoas ${ }^{(18)}$, pois o imunobiológico contra a hepatite B existe desde $1982^{(5)}$.

Convém ressaltar que a ampliação da vacina contra a hepatite $B$ para as faixas etárias de um a 19 anos ocorreu em 2001, o que passou a oportunizar uma maior prevenção ${ }^{(16)}$. A partir de 2016, a vacina foi universalizada para todas as faixas etá$\operatorname{rias}^{(14)}$. Não obstante, a baixa adesão vacinal dos casos notificados por hepatite $B$ interfere consideravelmente nos resultados $\mathrm{e}$ na implementação das possíveis políticas de prevenção e tratamento do agravo ${ }^{(12)}$. Pois, as notificações ocorridas no período de 1999 a 2016, mais da metade dos casos, $58,6 \%$ possuíram o registro da fonte de infecção com a opção ignorada ${ }^{(1)}$.

Para tanto, os registros de notificação dependem da interpretação do profissional responsável ${ }^{(3)}$, bem como do usuário do serviço, o qual pode não relatar os reais riscos a que se expõe, o que sugere um processo de abordagem e descrição mais detalhado no momento da exposição. Assim como, investimento na prevenção primária, incluindo vacinação e melhor controle de infecção, como aperfeiçoamento do processo de diagnóstico e manejo planejado dos casos confirmados ${ }^{(19)}$. Existe também um mecanismo que avalia a efetividade da vacina contra hepatite $B$ através do exame anti-HBs, contudo, diferente da vacina, o exame não é disponibilizado na rede pública de saúde, como rotina, após a vacinação.

Outro aspecto relevante incide na localização dos usuários infectados, os quais, na sua maioria, pertencem a zona urbana e recorrem aos Centros de Testagem e Aconselhamento (CTA), como também aos serviços de Atenção Primária em Saúde para receber o suporte devido nos seus municípios vinculados ${ }^{(17)}$. Convém salientar que os referidos Centros foram implantados no início da década de 90 pelo Ministério da Saúde, através do Programa Nacional de Infeções Sexualmente Transmissíveis e AIDS. Já a inclusão da testagem sorológica às hepatites virais nos CTA ocorreu a partir de 2004, contribuindo para a reestruturação da rede de
A partir dos

dados analisados

no período de

2011 a 2016, foi

possível verificar

que a linha de

tendência vem

se apresentando

uma crescente,

com um destaque

para 2016, em

que houve uma

duplicação no

número de casos

notificados em

relação a 2015. referência e a capacitação dos profissionais sobre os modos de transmissão, medidas de controle e interpretação de marcadores sorológicos desses agravos ${ }^{(14)}$.

Assim, conhecer a distribuição geográfica dos casos notificados permite visualizar a disposição destes, bem como, os vazios espaciais, onde não ocorrem as notificações, situação que pode também ser um indicativo de limitação de oferta assistencial, uma vez que novos casos podem não ser notificados por falta de acesso ao cuidado $^{(20)}$. Por conseguinte, a identificação do perfil dos casos notificados, a construção de mapas e o acompanhamento da adesão ao tratamento, são mecanismos de monitoramento e estímulo para o investimento de campanhas vacinais, bem como de ações educativas que visem a maior divulgação sobre os cuidados em saúde e possíveis comportamentos de risco para a infecção ao VHB.

\section{CONCLUSÃO}

A partir dos dados analisados no período de 2011 a 2016, foi possível verificar que a linha de tendência vem se apresentando uma crescente, com um destaque para 2016, em que houve uma duplicação no número de casos notificados em relação a 2015. Este aumento significativo está fortemente relacionado com as campanhas de prevenção da doença, o que deve ser enaltecido, pois elas possibilitam informar a comunidade em geral, sobre o real risco que o VHB traz para o indivíduo e, acima de tudo, sobre as formas de prevenir a doença.

O cenário desfavorável para a condição vacinal entre os casos notificados da pesquisa acendeu certa surpresa, principalmente por se tratar de uma doença que pode ser facilmente controlada com a vacina, e a mesma encontra-se disponível em qualquer unidade da Atenção Primaria em Saúde. Cabe então criar estratégias para ampliar a cobertura vacinal, sobretudo entre os adultos e na área urbana, grupo de maior vulnerabilidade para o agravo em Santa Cruz do Sul.

Conhecer o perfil da população acometida pelo VHB e, através do mapa, localizar 
tais resultados e orientar profissionais de saúde é um passo simples, porém de grande impacto para subsidiar a educação em saú- de, principalmente com relação à prevenção da doença, cuja atuação dos profissionais de saúde torna-se relevante, tanto como facili- tadores do processo de notificação, quanto de educadores frente à situação alarmante da doença no cenário da pesquisa. -

\section{REFERÊNCIAS}

1. Ministério da Saúde, Secretaria de Vigilância em Saúde. Departamento de DST, Aids e Hepatites Virais (BR). Protocolo clínico e diretrizes terapêuticas para hepatite B e Confecções [Internet]. Brasília, DF: Ministério da Saúde; 2017. [citado em 07 nov 2019]. Disponivel em: http://www.aids.gov.br/pt-br/pub/2016/ protocolo-clinico-e-diretrizes-terapeuticas-para-hepatite-b-e-coinfeccoes.

2. Carvalho LRB, Cruz JN, Coelho LS, Carvalho HEF, Lima CHR, Almeida CAPL. Prevenção da hepatite B: formação e atuação do enfermeiro de Estratégia Saúde da Família. Rev. Prev. Infecç. Saúde. [Internet]. 2015 [citado em 20 nov 2019]; 1(2):83-90. Disponível em: https://ojs.ufpi.br/index.php/nupcis/article/ view/4114/pdf.

3. Ministério da Saúde, Secretaria de Vigilância em Saúde (BR). Boletim epidemiológico. Hepatites virais 2018 [Internet]. Brasília, DF: Ministério da Saúde; 2018. [citado em 15 nov 2019). Disponivel em: http://portalarquivos2.saude.gov.br/images/ pdf/2018/julho/05/Boletim-Hepatites-2018.pdf.

4. Silva $A C B$, Souza LFB, Katsuragawa $T H$, Lima AA, Vieira DS, Salcedo JMV. Perfil soroepidemiológico da hepatite B em localidades ribeirinhas do rio Madeira, em Porto Velho, Estado de Rondônia, Brasil. Rev Panamazonica Saude. [Internet]. 2015 [citado em 21 nov 2019]; 6(2):51-59. doi.org/10.5123/S217662232015000200007

5. Organização Pan-Americana de Saúde. Organização Mundial da Saúde. Dia mundial da hepatite 2016: Conheça a hepatite e aja agora; 2016.

6. Centro Estadual de Vigilância em Saúde (Rio Grande do Sul). Divisão de Vigilância Epidemiológica. Programa Estadual de Hepatites Virais. Dia mundial de luta contra as hepatites virais 2018. Rio Grande do Sul: Secretaria de Saúde; 2018.

7. Ministério da Saúde, Secretaria de Vigilância em Saúde. Departamento de Vigilância, Prevenção e Controle das Doenças Sexualmente Transmissiveis, Aids e Hepatites Virais (BR). Manual Técnico para o Diagnóstico das Hepatites Virais. Brasília: Ministério da Saúde; 2018.

8. Silva, MGC da; Rouquayrol, MZ (Org.). Rouquayrol: epidemiologia \& saúde. 8. ed. Rio de Janeiro: Editora Medbook; 2018. 752p.

9. World Health Organization. Organização Pan-Americana de Saúde. Novos dados sobre hepatites destacam necessidade de uma resposta global. 2017. Brasilia, DF: Ministério da Saúde; 2017.

10. Assessoria de Comunicação da Prefeitura de Santa Cruz do Sul (Santa Cruz do Sul), Campanha de prevenção contra as hepatites virais ocorre do dia 26 a 29. Santa Cruz do Sul: Assessoria de Comunicação da Prefeitura de Santa Cruz do Sul; 2016.

11. Fontes AM, Ardisson JS, Souza MA, Freitas RR, Pancoto JA. Epidemiology of hepatitis $B$ virus in the cities of the northern region of Espírito Santo, Brazil.

An. acad. bras. ciênc. [Internet]. 2016 [citado em 10 nov 2019]; 88(3):1549-55. doi. org/10.1590/0001-3765201620150140.

12. Martins MMF, Veras RM, Costa EAM. Hepatite B no Município de Salvador, Bahia, Brasil: Padrão epidemiológico e associação das variáveis sociodemográficas. Rev. bras. ciênc. saúde. [Internet]. 2016 [citado em 10 nov 2019]; 20(3):189-196. doi. org/10.4034/RBCS.2016.20.03.03.

13. Gusmão BM, Pereira FS, Rocha AP, Fernandes MBS, Dias OV, Costa SM. Análise do perfil sociodemográfico de notificados para hepatite $\mathrm{B}$ e imunização contra a doença. Rev. pesqui. cuid. fundam. (Online). [Internet]. 2017 [citado em 15 nov 2019]; 9(3):627-633. doi.org/109789/2175-5361.2017. v9i3.627.633.

14. Ministério da Saúde, Secretaria de Vigilância em Saúde. Departamento de Vigilância, Prevenção e Controle das Infecções Sexualmente Transmissíveis, do HIV/Aids e das Hepatites Virais (BR). Diretrizes para organização do CTA no âmbito da Prevenção Combinada e nas Redes de Atenção à Saúde [Internet]. Brasília, DF: Ministério da Saúde; 2017. [citado em 07 nov 2019]. Disponivel em: http://www.aids.gov.br/pt-br/gestores/diretrizes-para-organizacao-e-funcionamento-dos-cta-no-ambito-da-prevencao-combinada.

15. Negreiros DEH, Vieira, D.S. Prevalência de hepatites B, C, sífilis e HIV em privados de liberdade - Porto Velho, Rondônia. Rev. Interd. [Internet]. 2017 [citado em 15 nov 2019]; 10(1):4352. Disponivel em: https://revistainterdisciplinar.uninovafapi. edu.br/index.php/revinter/article/view/1058.

16. Francisco PMSB, Donalisio MR, Gabriel FJO, Barros MBA. Vacinação contra hepatite $B$ em adolescentes residentes em Campinas, São Paulo, Brasil. Rev. bras. epidemiol. [Internet]. 2015 [citado em 13 dez 2019]; 18(3):552-567. Disponivel em: http://www.scielo.br/scielo.php?pid=S1415-790X2015000300552\&script=sci_arttext\&tlng=pt.

17. Dias JA, Cerutti Junior $C$, Falqueto $A$. Fatores associados à infecção pelo vírus da hepatite B: um estudo caso-controle no município de São Mateus, Espírito Santo. Epidemiol. serv. saúde. [Internet]. 2014 [citado em 03 nov 2019]; 23(4):683-690. doi.org/10.5123/S1679-49742014000400010.

18. World Health Organization. Global Hepatitis Report 2017. Geneva: World Health Organization; 2017.

19. Lanini S, Pisapia R, Capobianchi MR, Ippolito G. Global epidemiology of viral hepatitis and national needs for complete control. Expert rev. ant. infect. ther. 2018; 16(8):625-639.

20. Almeida EC, Gleriano JS, Pinto FKA, Coelho RA, Vivaldini SM, Gomes JNN, Santos AF, Sereno LS, Pereira GFM, Henriques SH, Chaves LDP. Acesso à atenção às hepatites virais: distribuição de serviços na região Norte do Brasil. Rev. bras. epidemiol. [Internet]. 2019 [citado em 10 nov 2019]; 22(Suppl 1):e190008. Disponivel em: http://www.scielo.br/scielo.php?script=sci_arttext\&pid=S1415-790X2019000200405\&lng=en. 